
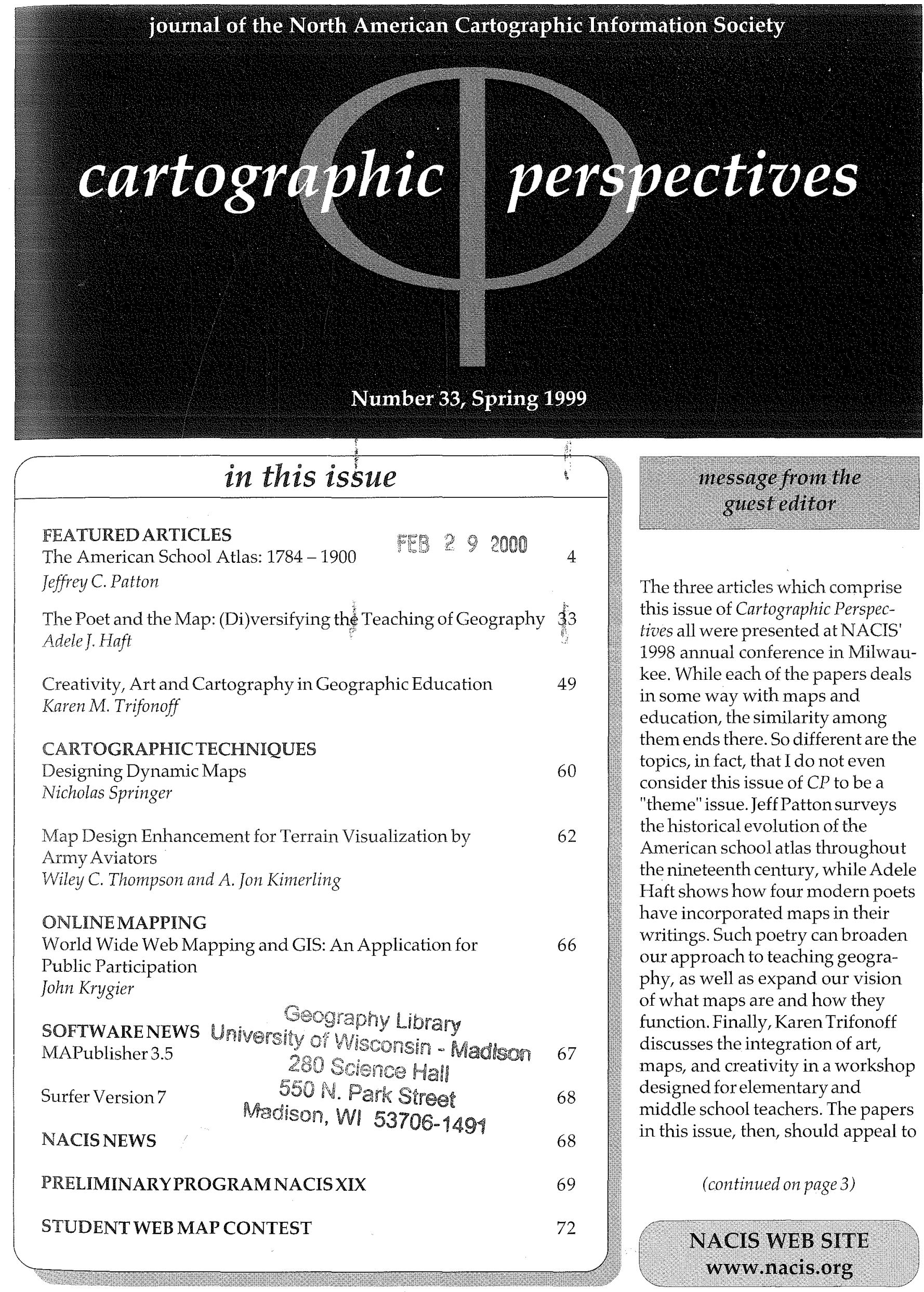

\title{
FEATURED ARTICLES
}

The American School Atlas: $1784-1900$

efreyC.Patton

The Poet and the Map: (Di)versifying the Teaching of Geography 33

Creativity, Art and Cartography in Geographic Education

\section{CARTOGRAPHICTECHNIOUES}

Designing Dynamic Maps

Map Design Enhancement for Terrain Visualization by

y Aviators

Wiley C. Thompson and A. Jon Kimerling

\section{ONLINEMAPPING}

World Wide Web Mapping and GIS: An Application for

Public Participation

rygier

SOFTWARENEWS

MAPublisher 3.5

Surfer Version 7 Madison, WI 53706-1491

$$
280 \text { Science Hall - Madsom }
$$

NACIS NEWS

68

69

2
The three articles which comprise this issue of Cartographic Perspectives all were presented at NACIS' 1998 annual conference in Milwaukee. While each of the papers deals in some way with maps and education, the similarity among them ends there. So different are the topics, in fact, that I do not even consider this issue of $C P$ to be a "theme" issue. Jeff Patton surveys the historical evolution of the American school atlas throughout the nineteenth century, while Adele Haft shows how four modern poets have incorporated maps in their writings. Such poetry can broaden our approach to teaching geography, as well as expand our vision of what maps are and how they function. Finally, Karen Trifonoff discusses the integration of art, maps, and creativity in a workshop designed for elementary and middle school teachers. The papers in this issue, then, should appeal to

(continued on page 3)

\section{NACIS WEB SITE www.nacis.org}


a diverse set of readers with a basic interest in maps.

It has been a few years since I was responsible for editing a journal, and the experience of editing this issue has reminded me of several things that I used to know but which had dimmed in my consciousness. In thinking about the health and viability of this and other cartographic journals, I would like to share - briefly - one aspect of my reflections with you: the importance of reviewers in the publication of a journal.

It takes several categories of people to publish an academic journal, of course - authors, editors, reviewers, and production staff, to name the most obvious ones. Of these, the authors and editors are the most visible, but academic journals depend equally on the more-or-less invisible reviewers, two or three of whom must pass judgment on every manuscript submitted for publication. Which of us, as either author or editor, has not felt a rush of gratitude at receiving a thorough, insightful, and timely review of a paper? On the other hand, most of us have probably also experienced the helpless frustration that accompanies a reviewer's unmet assurances that the review will be done "soon" or - worse - utter silence. Production deadlines are missed; authors are forced to wait many months, at times, to receive feedback on their work (which is especially unfair to young scholars facing tenure decisions); and editors howl at the moon. Almost as disappointing are reviews that are done so cursorily that they are virtually worthless.

Those of us who write for (and edit) academic journals can thank anonymous reviewers for making possible the publication of each manuscript. And in return, I believe, we have a professional responsibil- ity to serve as a reviewer for other scholars at times. As trite as it may sound, the publication process depends on qualified people doing their part in the review process as well as the writing process.

The fact that the papers in this issue of Cartographic Perspectives are being published less than a year after their first submission attests to the hard work done by the authors, reviewers, and production staff of the journal. I'd like to say thanks to all of them, and to Mike Peterson, our regular editor, welcomeback!

\section{Patricia Gilmartin \\ Guest Editor \\ Professor, Department of Geography University of South Carolina gilmartin-pat@sc.edu}

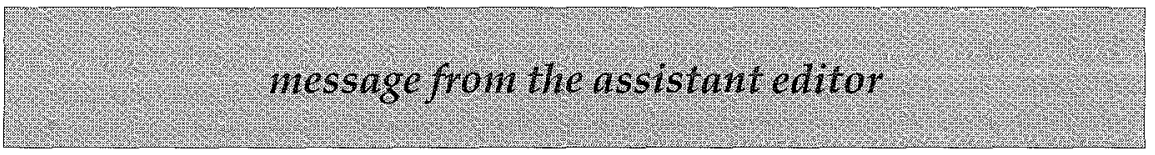

The Fall 1998 issue of Cartographic Perspectives (Number 31) was guest edited by Trudy Suchan. Her name was inadvertently omitted from the guest editor message at the beginning of the issue. Trudy is a graduate of the Pennsylvania State University and is currently with the U.S. Bureau of the Census.

NACIS is very appreciative of the contribution that guest editors make to $C P$. My apologies to Trudy for this omission. 